\title{
Peritonitis meconial
}

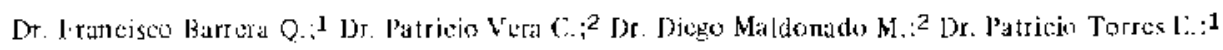
tyris. I lizabeth Lyon ‥1 Mar. Maria Ortiz Y.; 3 Dra. Mercedes Ruiz, ].4

\section{Meconium peritonitis}

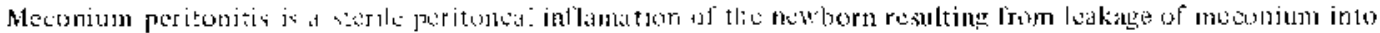

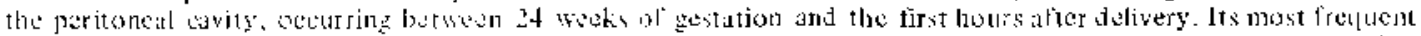

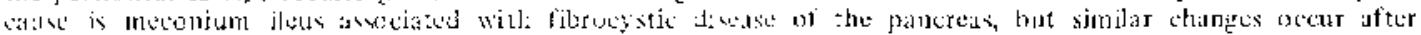

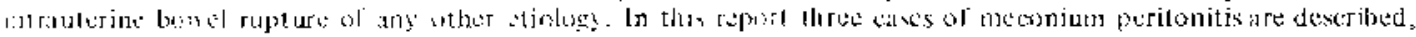

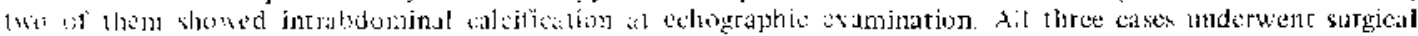

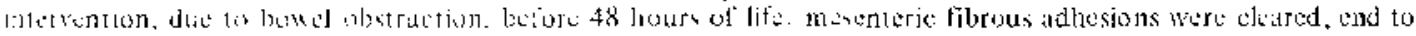

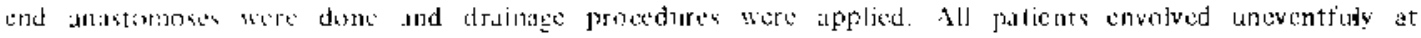

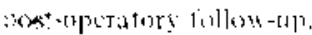

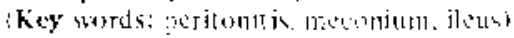

Lia peritonitis meconial, si ha definido, como aquella que ocurre entre las 24 semanas de edad gestacional y las prisucras horits de vida postnatal, antes que se produzca lá wolonización bacteriana intestinal. Siendo unid entidad poeo fricuente. debe considerarse como uni manifestación clínca de obstruccion intestinal congénita y exasionalmente en nuestro medios. de lí istemediad fibroguistiea mucrwiscidosis.

La incorporación, dentro de los métodos de diagnostico prenatal. de la ullrasonografia, Ja permitido, cuando existen calcificaciones intra. abdominales fetales, su Jiagnistico precos y mitnejo médico-quir úrgico uportuno.

Se presentan tres casos de peritonit is meco. nial, dos de ellos con deteción prenatal ultrasonográfica de caleificaciones intraabdomınales. observados en la unidad de neonatología del Hospital Paula Jaraquemada en el perjodo comprendido culre agosto de 1986 y abril de 1987.

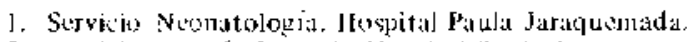

2. Service Corugja Intantil Hospital Palata fiodtuemada.

3. Marma Superqisora Servicio Neomatologáa. Hoxplata] Paula Jaraquimada.

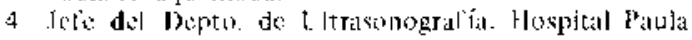
Jaraytumidial.

\section{Casos clínicos}

1. Recićn nacido (RN) pretćrmino, cdid gestacional 34 semanas. peso adecuado, sexo masculino. Cevírea por ailestasia materna, $\Lambda$ pgar 7 al minuto, peso $3.150 \mathrm{~g}$. talla $44 \mathrm{~cm}$. Antecedente de hallargo ecografico prenatal de masa intraabdominales cátcificallas. Su abdomen má tenso, distendido y tenia in: a: masa Jura, periumbilical. de $3 \times 4 \mathrm{~cm}$. Inmediatamente después de nacer presentó sindrome de dificultad respiratoria por to que lue conectado a sistema de presión positiva continua en la vía aérea (CPAP), evolucionando lavorablemente, desde el punto de vista respiratorio (figura 1 ).

$A$ las $20 \mathrm{~h}$ de vida la radiografía (rx) de abdomen simple mostraba la existencia de calcifjcacioncs intraabdominales $y$ signos de ruptura de víscera hueca (figura 2), practicándose laparotomía exploradora, an la que se encontró cantidad de neconio libre, perforaciones intestinales múltiples cubicrtas con meconio calcificado, adlierencias intestinales, y algunas asas intestinales de color violáceo y atrófico. Se realizó asco, disceción quirúrgicu de bridas y adherencias, rosección intestitral, sutura de intestino término-terminal $y$ drenaje. La ewolución postoperatoria fue sit isfactoria, manejandose con alimentación parenteral 


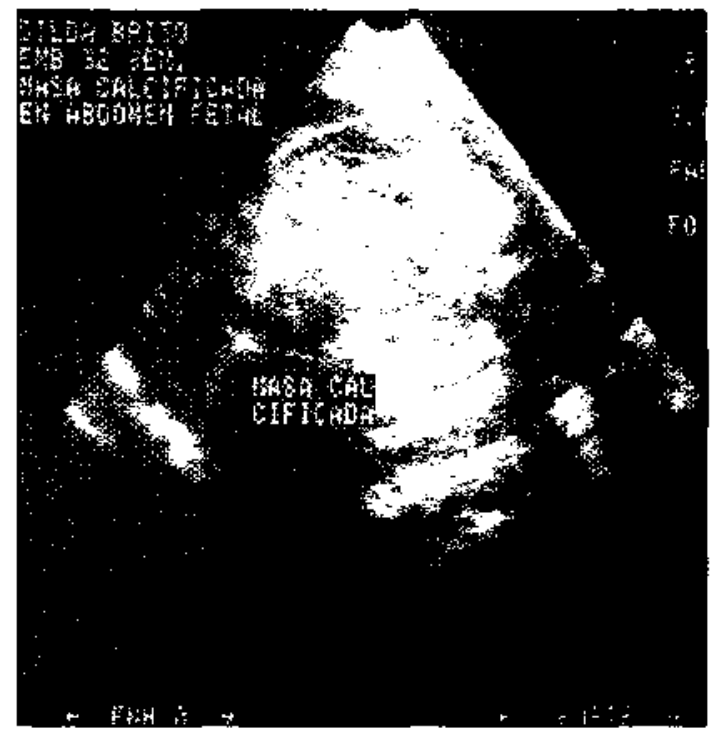

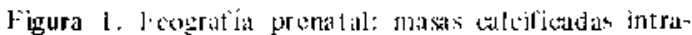
alydominaley.

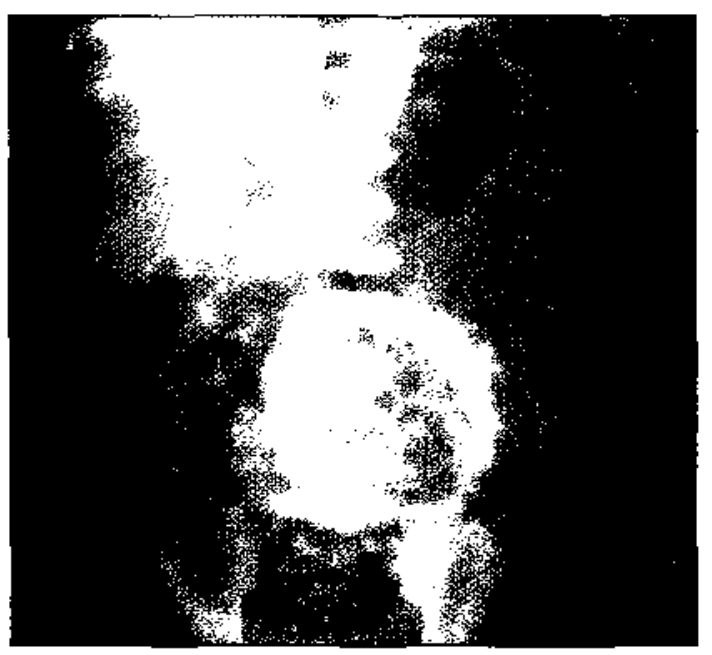

Figura 2. Signos de suptura de víscerá hueca y masa calcilicada intra-abdominal.

total hasta el $6^{\circ}$ día. cuando se inició la alimentación oral, con buena tolerancia. Se dió de alta, en excelentes condiciones, pesando $2.000 \mathrm{~g}$, a los 23 dias de vida. Su seguimiento clínico ambulatorio, hasta los 8 meses de edad, ha sido favorable, tiene buen estado de nutrición. Sulrió hernia inguinal que se reparó a los dos meses de edad. Posteriormente tuvo una crisis de obstrucción intestinal parcial que se resolvió espontánẹ-

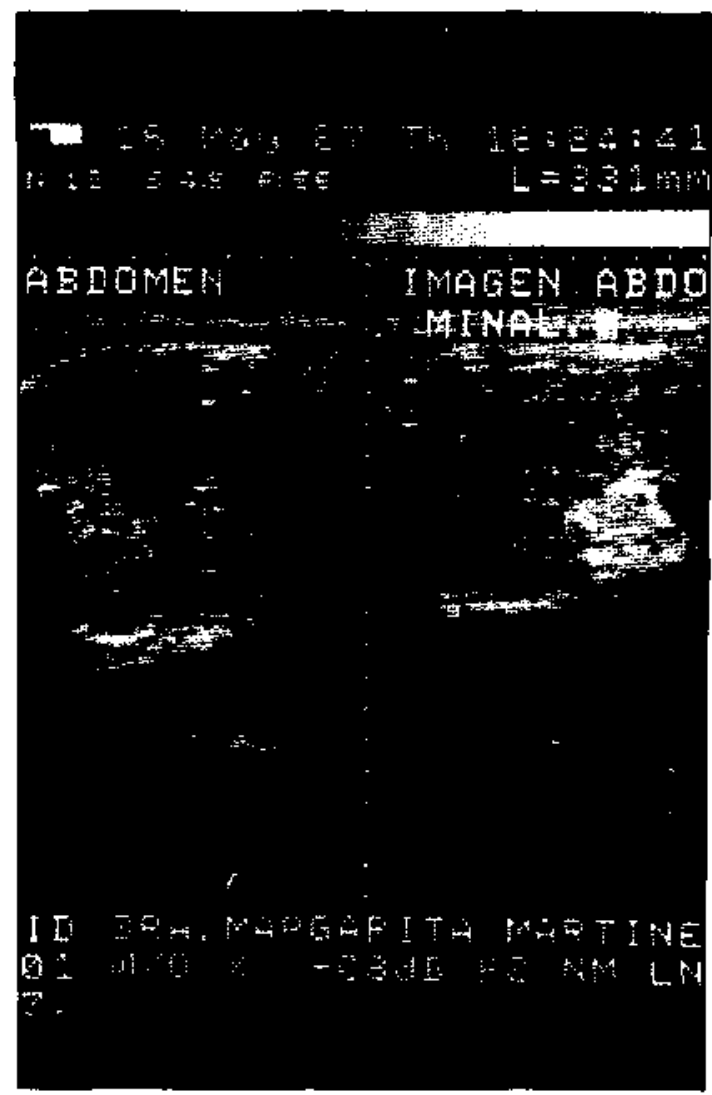

Figura 3. Jicografíi prenatat: masa calcitîcada en lemiabdomen inferior, hacia la derecha de la linea ınedia.

mente. Las mediciones de electrolitos en sudor resultaron normales.

2. Recién nacido pretérmino, edad gestacional 37 semanas. sexo masculino, parto eutócico, Apgar 9 al minuto, peso $3.300 \mathrm{~g}$ (adecuado), talla $50 \mathrm{~cm}$. Ingresó por el hallazgo ecográfico prenatal a las 25 semanas de gestación, de una masa calcificada en el hemiabdomen inferior, en la derecha de la línea media, de tamaño $3 \times 3 \times$ $2.7 \mathrm{~cm}$ (figura 3) plantcándose en dicho momen. to el diagnóstico de peritonitis meconial. En el ingreso el abdomen era simétrico, depresible, indoloro, no se palpaban masas; los ruidos hidroaéreos estaban presentes y había eliminación de meconio. De acuerdo con el equipo quirúrgico, se le dió alimentación oral, previa medición de residuo gastrico. A las 20 h de vida en la radiogra. fía do abdomen simple se encontraron imágenes compatibles con peritonitis meconial (figura 4) no observándose ruptura de víscera hueca. En las 


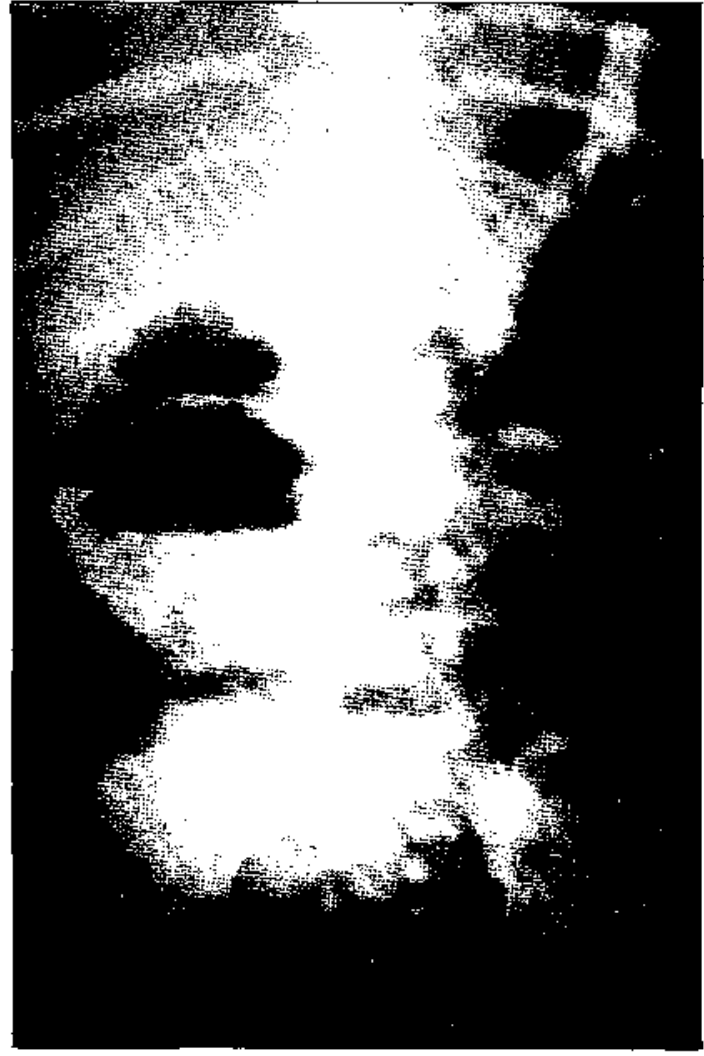

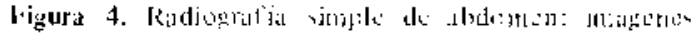

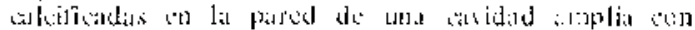

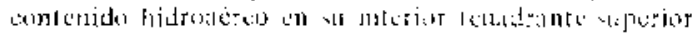

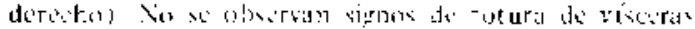
huteids.

primeras 48 lionas da vida evolucioni sia problemas, posteriormente prisentó manifestaciones clinicas de obstrucción incestinal parcial (vómitos biljosos, distension abdominal). Las radiografias de abdomen simple de control, revelaron aumentos de los niveles hidruatreos, con lo que se decidio la intervención quirugica, en la que se encontró ur plastrón. que cubría cavidad que contenia líquido intestiual y una formacion pxidoquística subhepática en zayo interior hab úl una asa necrótica de ileon terminal de $8 \mathrm{~cm}$ de longitud. Se efectuó liberación de adberencias, resección al segmento necrótico, aseo, sutura término-terminal y drenaje.

Después de 48 loras de buena evolución. presentó signos clínicos de infección de la herida operatoria $y$ apareció una fístula estercordiced. Se manejo con alimentación parentcral total $y$ antibiólicos, iniciando la alimentación oral a $8^{\circ}$

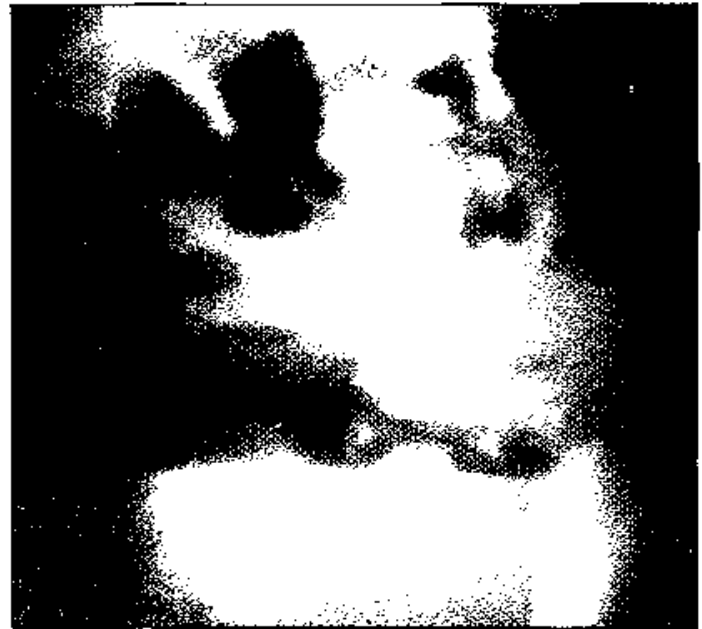

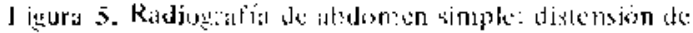

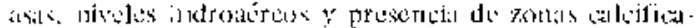

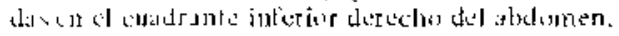

dia. cou buena tolerancia. Su evolución la sido tórpida, pero con tendencia a la recuperación. Actualmente tiene 7 meses de edad, dewnutrición de griddo II $y$ tránsito digestivo normal. Ha salfido obstrucciones intestimales parciales ocasiculaics que comprometen el estado de nut rición siencle réintervenido en und oportunidad para efictuar nueva sección de bridis. Los electrolitos del stidor sun normales.

3. Reciśn nacido pretérmino, cáad stestaciona] 35 semants, peso adecuado, sexo femenino, cosírea par presentaciótl podálica. Apgar 3 al minulis y 7 a los 5 minutus; peso $1.970 \mathrm{~g}$, talla 4. $\mathrm{cm}$.

Hospitalizado por prematuridad, depresión neonatal severa recuperada y signos iniciales de difjultad respiratoria. Exolucionó sin problemas en las primeras 48 horas de vida. Después presentó signos clínicos de obstrucción intestinal (vómitos biliosos, distensión abdominal, ausencia de expulsión de gases por recto). En la radiografía de abdomen simple se encontró distensión de asas y zonas calcificadas (figura 5). Se intervino quirúrgicamente, observándose abundantes calcificaciones en el peritoneo parietal y el mescnterio, segmento yeyunoileal distendido y valvulado, colon derecho hipoplásico. Se realizó resección intestinal con anastomosis término-terminal. aseo y drenaje. El diagnóstico postoperatorio fue obstrucción inteslinal alta coml atresia yeyunoilcal y per itonitis meconial. 
Evolucionó satisfactor iamente, manejándose con alinentación parenteral total; al $6^{\circ}$ dia se inició alimentación oral, con buena tolerancia. Pesaba 1.950 g a los 13 días de vida.

\section{DISCUSION Y COMENT ARIO}

Las primeras descripciones de peritonitis meconial, fueron heclas por Morgagni en 176] y posteriormente por Simpson en 1838, actualmente se define como una peritonitis química aséptica, que puede producirse entre las 24 sema. nas de gestación y las primeras horas de vida postnatal, antes de la colonicación bacteriana postnatal. ${ }^{1,2}$

Entre sus etiologias, se describen mallormaciones obstructivas del tubo digestivo. principalmente del intestino delgado, tales como: atresia. vólvulo, inqaginación, insuficiencia vascular, duplicación, estenosis, bandas congćnitas, ano imperforado, divertículo de Meckel, enfermedad de Hirschprung. ${ }^{3.4}$

En aquellos paises en que la fibrosis quística se deseribe won nayor frecuencia como entidad clínica, ésta debc ser considerada en la etiología, debiendo efectuarse siempre un estudio del meconio y de clestrolitos en el sudor para descartar dicha posibilidad. En 50\% de los casos, no es posible identiticar una causa para la perforación idiopática. ${ }^{3.6}$

Los hallazgos patológjeos pueden clusificarse en tres lipos: La'variedad fibro adhesiva es la más frecuento y resulta de una reacción fibroblástica int ensa, en respuesta a la perforación e irritación quimica, debida a la acción de enzimas digestivas $y$ del meconjo. La obstrucción es producita por la acción de bandas adhesivas. La forma quistica ocurre cuando la reacción fibroblástica no es suficiente para sel lar el sitio de la perforación, las asas intestinales se fijan y forman una delgada pared que sinula una cavidad quística que contienc meoonio y secreción intestinal. El tamaño del quiste depende de la rapider con que el intestino circundante forma una cavidad virtual y de la edad fetal en que se produce la perforación. Se produce calcificación de la pared del quiste e incluso de su contenido. Los quistes de mayor tamajo pucden causar distensión y masas abdo. minales palpables. En la peritonitis meconial generalizada la perforación ocurre en el período perinatal, justo antes o durante el nacimiento. ocasionando una peritonitis, que excepto por su naturaleza aséptica, es similar a la observada en adultus con úlcera péptica perforade. El meconio y el exudado visceral se distribuyen libremente en la cavidad peritoneal y suele contener grandes cantidades de sales cálcicas. Las adherencias entre las asas int estinales son más fibrinosas que fibrosas pero no ha habido tiempo para la formación de calcificaciones, ${ }^{1,3,4}$

Los signos dínicos corresponden a los de obstrucetion intestinal y ascitis, rara ve 2 a peritonitis, destacando la distension abdominal, las alteraciones del tránsito digestivo (vomito bilioso $y$ retardo en la eliminación de meconio) y ocasionalmente, masa palpable, que puede confun. dirse con las de origen renal. Se hia insistido en que pudiers ser un signo patognomónicu en el varón, la presencia de calcificaciones en la túnica vaginal del escroto..$^{3-7}$

En tos casos en que se retrasa el diagnóstico, la sobreinfección bacter iana suele complicar la cro. lución, con aparición de cambios de coloración periumbilical $\mathrm{c}$ incluso thanifestaciones clínicas de sepsis.

En la actualidad, el diagnóstico puede ser anticipado, prenatal, cuando en la ultrasonografía obstétrica se observan calcificaciones intraabdomiriales o escrotales, $o$ ambas en el feto.

Se ha descrito cjerta variedad de signos ultra. sonográficos en la peritonit is meconial, incluyen. do evidencia de ascitis fetal, polihidroamnios, masas focales abdominales y seudoquistes. Sin embargo una mitsa detectada en la ecografía prenatal debe alertar al sonografista y al clínico sobre la posibilidad de una peritonitis meco. nial. ${ }^{7,8}$

La facilidad con que es posible hacer el diag. nóstico de peritonitis meconial cn útero, permite preparar a la familia para problemas potenciales $y$ proporcionar al equipo módico medios para prevenir complicaciones como disturbios electrolíticos, peritonitis bacteriana y shock séptico. ${ }^{4}$

En el período postnatal, la radiografía de abdomen simple anteropostcrior y lateral es una ayuda importante en el diagnóstico: en los recièn nacidos con perforación abierta, la presencia de aire dentro del abdomen, por lo general bajo el diafragma, tiene gran valor y en la mayoría de los ersos. a causa de las frecuentes calcificaciones del meconto derramado, pueden verse placas de calcificaciones distribuidas por toda la cavidad peritoncal que alcanzan excepcionalnente el escroto ${ }^{6}$ y cuando se cncuentran se consideran patognomónicas $y$ de peritonjt is meconial. La historia obstétrica con polihidroamnios y distosia, 
es común en esta entermedad. ${ }^{3}$

Antes de realizar en estos niños una intervención quirúrgica es necesario vaciar el estómago por aspiración, corregir la deshidratación, los desequilibrios electrolíticos y la insuficiencia circulatoria. La descompresión mediante paracentesis abdominal y la admúnistración de oxígeno, puede ser útil para combatir el compromiso de la función pulmonar causado por grandes distensiones abdominales en estos casos.

El tratamiento de regla es la intervención quirúrgica, para la reparación del tránsito intes. tinal y el drenaje de la cavidad peritoneal. Es necesario a veces efectuar resecciones intestinales $y$ anastomosis término-terminales con el objeto de conseguir superficies al menos mínimas para las funciones de absor ción, ${ }^{3-6}$

Una vez que el niño egresa de pabellón, se inicia alimentación parenteral, aproximadamente por 6 días, tiempo necesario para la reparación intestinal operatoria, comenzando luego con aportes crecientes de alimentación oral, de baja osmolaridad y sin lactosa en las primeras etapas.

Ocasionalmente, pueden acurir en la evolución posterior manifestaciones de suboclusión intestinal, por bridas o adherencias postoperatorias.

La mortalidad de la peritonitis meconial ha disminuido desde $85 \%$ en el año 1955 hasta $50 \%$ actualmente. ${ }^{4}$ No cabe duda que, como en muchas afecciones del recién nacido, las nuevas técnicas de diagnóstico pre y postnatal, se traducirán en un manejo médico y quirúrgico más adecuado y oportuno.

\section{RESUMEN}

La peritonitis meconial es una inflamación estéril, química, del peritoneo, causada cominmente por perforación intrauterina del intestino delgado, asociado frecuentemente al ileo meconial de la muooviscidosis u otras lesiones obstructivas o malformaciones. Clínicamente predominan los signos de obstrucción intestinal. El diag. nóstico prenatal es posible mediante ultrasonografía que, junto con la radiografía de abdomen simple es también un medio de gran utilidad en la identificación postnatal del problema. Et tratamiento quirúrgico es siempre necesario para resolver la obstrucción.

\section{REFERENCIAS}

1. Foroubor F.: Meconium Peritonitis: Pathology evolution and Diagnosis. Am J Clin Pathol 1982; 78: 208-213.

2. Dodat H., Chappuis J.P.; Dauder M., Bertix ${ }^{*} L$. Eury M.I., Dalery F.: Les Peritonitis Meconiales Chir Pediats, 1979; 20: 21.26.

3. Lorimer W.S., JP., Ellis A.G.: Meconium Peritonitis. Surgery 1966;60:470-475.

4. Mancarrow P., Mattrey R., Edwards D., Skram C.: Fibroadhessve Meconium Peritonitis: in utero Sonographie Dingnosis. J Ultrasound Med 1985; 4: 213-215.

5. Mc Gaham J., Hanson F.: Meconium Peritonitis with accompanying Pscudocyst: Prenatal Sonographic Diagnosis. Radiology 1983 ; 148: 125-126.

6. Bailey $H_{\text {.: }}$ Peritonitis Meconjal. Cirugía de Úrgencia, $8^{a}$ Edición, Buenos Aires, Argentina, 1970.

7. Kemmey P.J., Spirt B.A., Elis D.A., Patil V.: Scrotal Masses Caused by Meconium Peritonitis Prenatal Sonographie Diagnosis. Radjology 19.85; 154: 362 .

8. Garb M, Rad F.F., Riseborough J.. Meconium Peritonitis presenting as Fetal ascitis on ultrasound. Br $\rfloor$ Radiol 1980; 53; 602-604. 